\title{
Compensation Still Matters: Language Learning Strategies in Third Millennium ESL Learners
}

\author{
Alireza Shakarami \\ English Department, Islamic Azad University, Kazerun Branch, Kazerun, Iran \\ Karim Hajhashemi and Nerina J. Caltabiano \\ James Cook University, Australia
}

\begin{abstract}
Digital media play enormous roles in much of the learning, communication, socializing, and ways of working for "Net-Generation" learners who are growing up in a wired world. Living in this digital era may require different ways of communicating, thinking, approaching learning, prioritizing strategies, interpersonally communicating, and possibly developing compensatory techniques for information gaps among other categories of Language Learning Strategies. The Net-Geners, therefore, need new skills and new strategies to perform successfully as learners and workers. This study uses a mixed-methods approach that includes concurrent quantitative and qualitative data (i) to identify the Net-Generation learner's strategy preferences based on the "Strategies Inventory for Language Learning" (SILL) categories currently considered the most comprehensive strategy inventory and (ii) to identify possible emergent compensation strategies among Net-Geners, as a comprehensive study of the strategies used by the Net-Geners is clearly beyond the scope of this article. The results indicate that compensation strategies have undergone a number of modifications and are used differently by the Net-Geners in order to compensate for their knowledge gap and to help enhance their ESL learning.
\end{abstract}

Keywords: Net-Generation, modification, emerging, language learning strategies, compensation strategies, ESL

Shakarami, A., Hajhashemi, K. \& Caltabiano, N.J. (2017). Compensation still matters: Language learning strategies in third millennium ESL learners. Online Learning, 21(3), 235-250. doi: 10.24059/olj.v21i3.1055

\section{The Net-Generation}

\section{Introduction}

To date, the research in the field of language learning strategy has attempted to increase our knowledge about the processes learners employ within the classroom context, the dominant setting for learning over the last two decades, to develop their skills in a second or foreign language (Ardasheva \& Tretter, 2012; Breen, 2014; Dörnyei \& Ryan, 2015; Rezaei, Derakhshan, \& Bagherkazemi, 2011; Tang \& Tian, 2014; White, 1995). The Net-Generation language learners seem to largely neglect outside criteria that may impact the language learning process. Based on research findings, language learning strategies (LLS) differ relative to learner factors such as the respondents' level of proficiency (Chamot \& Kupper, 1989; Hajhashemi, Shakarami, Anderson, Yazdi-Amirkhiz, \& Zou, 2013; Radwan, 2011; Salahshour, Sharifi, \& Salahshour, 2013) and 
gender (Dunne \& Martin, 2006; Radwan, 2011; Salahshour et al., 2013). As education has embraced the digital learning environment, there has been a commensurate increase in the proliferation of learner strategies. According to Oxford (1990), compensation strategies refer to the learner finding synonyms from the context of the reading and relying on non-verbal communication, such as gestures, to communicate meaning when the exact meaning of a statement is not understood. Compensation strategies may include the use of emoticons to convey meaning in the digital media. Emoticons are the iconic images used in various social networking sites to show emotions. Identification of possible emerging new compensation strategies are the main concern of this study. It is presumed that the new millennium learners and workers may need new skills and strategies to perform successfully in the readily accessible knowledge. It can be argued that "Net-Generation" (Oblinger \& Oblinger, 2005) learners, who function in an era when much of the learning, communication, socializing, and ways of working take place through digital means may require new ways of thinking, ways of approaching learning, strategies, and priorities to compensate for their information gaps.

\section{Language Learning in the Net-Generation}

In order to understand Net-Generation language learning it is important to consider some of the theoretical perspectives of both first and second language acquisition theories. First, the theories on first language acquisition will be presented in order to provide a brief historical context. The systematic study of language began in earnest in the $19^{\text {th }}$ century. An early theory regarding first language acquisition is the Critical Period Hypothesis. The Critical Period Hypothesis, credited to Lenneberg working in the late sixties (see Heidar, 2012), sets a beginning age for language acquisition at around 2 years and a proposed end point of around puberty. The work of the behaviourists influenced linguists to conceive of language acquisition as the acquisition of habits through imitation and stimulus-response conditioning. The notion of individuals possessing a universal grammar containing a language acquisition device ushered Noam Chomsky's rationalist approach to language acquisition. Empiricists such as Piaget considered language acquisition as a developmental process, where children noted patterns within their environment and engaged in sense making of the world around them. Later, cognitivists emphasized the role of mind. According to cognitive theory, information is selected, organized, and integrated into prior understanding. In this way, learners accumulate new knowledge and have the capacity for reflective practice (Chamot, Barnhardt, El-Dinary, \& Robbins, 1996; Chamot \& O'Malley, 1994; Mitchell, Myles, \& Marsden, 2013; Prakongchati, 2007; Shakarami, Abdullah, Abdullah, \& Hoon, 2011). Learning in cognitivism involves the deliberate use of new material to modify and update pre-existing beliefs and ideas (Wenden, 1991). Other theories, like social cognitivism (Bandura, 1992) and social constructivism (Vygotsky, 1978), build on learners' interaction with environment and culture and their individual reflection for effective learning.

The theoretical framework for this study, which is the Constructivist philosophy of learning, is based on the premise that individuals construct their knowledge through their interaction with the environment. The basic idea is that learners construct their own knowledge by associating new information with already existing cognitive knowledge. The importance of learners' interaction with their social and physical environment is emphasized. The learner is considered central in the learning process while the teacher is seen as a facilitator or a guide (Vassiliki \& Marie-Josee, 2005). 
In a paper by Chapelle (2009), a number of second language acquisition theories were presented. Of particular interest were the psycholinguistic and the general human learning theories. Processability theory argues "that certain hypothesized psycholinguistic processes are responsible for comprehension and acquisition" (Gass, 1997 cited in Chapelle, 2009, p. 745). Input processing theory focuses on how the language is processed and how form-meaning connections are made (VanPatten, 2015). Within the general human learning theories, two perspectives, namely, Ellis's associative-cognitive CREED framework (cited in Mitchell et al., 2013), and DeKeyser's skill acquisition theory (DeKeyser, 2015), appear pertinent to this discussion. The associative-cognitive CREED framework relies on learners' recurring exposure to language examples. Skill acquisition theory relies on learning through constant practice and uses cognitive psychology principles. NetGeneration learners have the ability to connect to others without time and space restrictions. Their constant connection leads to frequent exposure, more interactions, and, ultimately, better language learning. Furthermore, Net generation learners have a tendency toward online and digital facilities which can help them learn better. Learners, to practice their English language, use live chat rooms, social networking, and other online connective measures to get in touch with others, including their friends, more knowledgeable peers, teachers, and other native speakers. Moreover, the widespread use of digital gadgets, including smart phones, makes it both necessary and comfortable for users to learn English.

Net-Generation language learners, faced with the requirements for, and opportunities of, a more self-directed environment, need to develop an awareness of the process of language learning and an understanding of their role in the shared learning spaces. Hauck (cited in Hauck \& Hurd, 2005) points out that "online language learning makes learners aware of themselves, their attitudes, aptitudes and beliefs and of the affordances of the learning environment and the degree to which they demonstrate flexibility and control" (p. 4). Digital age language learners are more selfdirected and can determine the types and arrangement of tasks they choose to work on and disregard tasks or sections of materials they do not consider useful for the development of their target language abilities. Additionally, the characteristics of Net-Generation learners (their collective and team-based tendencies), make it comfortable and preferable for them to work, play, talk, and learn as a group rather than as isolated individuals. This could apply to language learning settings as well.

Knowledge for digital world learners is constructed, not transferred, and learning is considered as an active, creative, and socially interactive process (Hampel \& Baber, 2003, p. 39). The roots are in the Constructivist movement of Cognitive Psychology, which argues that through experience, maturation, and interaction with the environment, people construct their world understanding (Rovali, 2004). Based on the Constructivist's point of view, the learner is an "active processor of information," in sharp contrast to Behaviourism, which considers the learner as a mere recipient of information. In the Constructivist's view, all individuals build their own concept of reality and, therefore, disparate ways of knowing and describing are equally legitimate (Spivey, 1997)

This study follows the principles of constructivism regarding the exploration of knowledge and believes that students themselves should be responsible for their learning. Students should not be "spoon-fed" by teachers, and should be trained to feel responsible for their own learning and to explore the new language they learn. Therefore, this study takes "learning" and "ways to learn learning" as its main theme and wishes to replace this system for "teaching language." In short, that is why the LLS were used in the study. 


\section{Language Learning Strategies}

Language learners often use learning strategies with the explicit goal of improving their knowledge and understanding of, and competence with, a target language. The strategies have been defined as the conscious thoughts and behaviours used by students to facilitate the accomplishment of language learning tasks and to personalize the language learning process (O'Malley \& Chamot, 1990). Although Chamot (2005) suggests the use and instruction of strategies for the benefit of lower achievers in the classroom, which was possibly the primary objective of the strategies studies, research in the field has concentrated less on the ways LLS are utilized by pre-internet and especially Net-Generation learners. The first author studied the various ways LLS are used by the Net-Geners compared to strategies employed by pre-internet language learners reported in the literature and found that the strategy difference scope is widely stretched on all of the six strategy categories reported by Oxford (1990) for pre-internet language learners. The main concentration of this paper is on possible differences of compensation strategies used by Net-Generation language learners, because there is a need to understand how Net-Generation learners manipulate, express, and employ compensation learning strategies in an online environment where a lack of face-to-face contact may impair smooth communication flow.

\section{Learning through Strategies}

Most of the taxonomies developed in the domain of LLS, even in the pre-internet era, placed emphasis on cognitive and metacognitive strategies with less attention to the compensational side of the learning process. Edstrom (2013) found that students confronted with the challenges of second language acquisition engaged in metacognitive activities such as "asking classmates, consulting reference materials, and modifying their original ideas to manage the task" (p. 274). How such metacognitive activities may translate with the use of digital devices is worthy of consideration. Furthermore, the verbal and nonverbal performances of the learners are downgraded as they compensate for information or knowledge gaps in the language learning process. In fact, communication of meaning through compensatory means is less a concern in the development of LLS inventories that are developed from their contemporary and dominant learning theories.

While emphasizing that language learning is not just a cognitive process and asserting that affective/social aspects of language learning are indispensable parts of LLS studies, Oxford (1989) developed her now widely used and comprehensive strategy inventory for language learning (SILL). The SILL encompasses six groups of LLS, including memory, cognitive, compensation, metacognitive, social, and affective strategies that interact in the enormous task of language learning. This study attempts to identify how Net-Generation ESL language learners use compensatory strategies while on forums, online discussions, interactions, and networking in the absence of eye contact and other facial gestures that seem necessary for nonverbal communication of meaning.

\section{Research Design}

\section{Methods}

The study employed a mixed-methods approach. It incorporated a questionnaire for the quantitative component, and used a semi-structured questionnaire to guide the in-depth interview for the qualitative component of the study. Quantitative instruments elicit numerical values which 
show that some of the LLS, namely cognitive or metacognitive, were of greater use and implementation; however, this study had a more detailed and deeper objective, that is, to identify how compensation strategies were used or replaced in a setting with no face-to-face contact. It was therefore necessary to probe participants for information that has mostly been neglected thus far. Accordingly, an additional part, namely, analysis of online interaction in a language forum, was added to the research. In order to participate in the study, students were required to fulfil two inclusion criteria, namely, that they were educated under the new Malaysian system of high techbased education, and that they were learning English as a second language in an academic setting.

\section{Participants}

A randomly selected representative sample of 107 undergraduate Net-Generation students learning English as a Second Language (ESL) from the language faculty of a Malaysian university participated in the study. The selected classes were from language and ICT courses. Students were enrolled in a variety of subjects and had different language learning classes but were instructed together. They were all approximately 21 years of age. Although both genders (females $(n=98$, $91.6 \%)$; males $(n=9,8.4 \%)$ ) participated, the sample was heavily skewed towards female participants. For the purpose of the qualitative component of the study, 20 participants were randomly selected from the original sample.

\section{Materials}

In order to identify the participants' compensation strategy use and preferences, Oxford's SILL (1989) questionnaire was used, as it is the most frequently used and most comprehensive instrument to date (Cohen \& Macaro, 2008; Hsiao \& Oxford, 2002; Oxford, 1990). The selection of the Oxford SILL was based on the fact that the data provided by the SILL relates to what we already know about the learning strategies of "baby boomers" (Oblinger \& Oblinger, 2005) and not the current Net generation in the literature. In fact, what is new here is that the data is elicited through other instruments, such as semi-structured interviews and observation of the online communication of the respondents in a forum. All the online conversations were saved on the university server to which the researchers were permitted access for the purpose of this research. New data emerged regarding the Net-Generation as a result of their inclination toward the use of internet and web-based activities. The only reason they are compared to the data gained from SILL is to find out what new aspects of already existing strategies or what possible new strategies are at the center of attention of the current Net-Generation language learners, considering digital affordances. Therefore, the use of SILL established a basis for comparison. Although the authors could have used the result of the research done by others for comparative purposes, they preferred to administer the SILL to re-establish already existing learning strategies and then compare results with new data from other research instruments of this research to observe trends. The qualitative data were obtained via a semi-structured questionnaire containing 25 items about the strategies students use in their online language learning environment. In particular, the focus was to ascertain how they compensate for any knowledge and information gaps, and how they communicate affect in the absence of face-to-face contact. Specifically, the open-ended items were: 1) When you need information or need an idea to solve a problem, what do you generally do? 2) What is your major source of information and ideas?

\section{Data Collection Procedure}

All students completed the Oxford's SILL questionnaire in their own time. The sub-group of 20 students was organized into five groups of four students. They completed online interaction 
texts regarding a language task in which they had to participate in an online forum and cooperate to find 30 ordinary language terms and their different meanings relevant to information and communication technology (ICT) as task 1. Data collected using the various methods were analyzed (i) to compare the qualitative data with SILL data, and (ii) to find the compatibility of the SILL compensation strategies with the needs of ESL learning in the digitally connected world of today, and (iii) to identify possible emerging compensation strategies among the Net-Generation ESL learners.

\section{Results and Discussion}

Net-Geners' compensation strategy preferences were classified using Oxford's (1989) compensation strategy categories as a basis. The SILL results were then compared to qualitative data from the interview transcript excerpts and online interaction texts, thus ensuring the triangulation of data. Compensation Strategy preferences obtained from the SILL is $(\mathrm{M}=3.59)$. According to Oxford's (1990) explanation, the strategy use is considered high if its mean value $(M)$ is between 3.5 and 5.0 , medium for mean values between 2.5 and 3.4, and low for values between 1.0 and 2.4. Accordingly, the value figure for use of compensation strategies reported here is considered high. It should also be noted that all participants' names are pseudonyms and that the reported excerpts are reproduced verbatim except where indicated.

\section{Compensation Strategies}

Compensation strategies as language problem-solving techniques consist of various mental or physical activities carried out by students to resolve any language learning problems they encounter, and are divided into guessing intelligently and overcoming limitations in speaking and writing (Oxford, 1990). Data from the SILL indicate the use of components of compensatory strategies as follows: Guessing $(M=4.08)$, Using gesture $(M=3.97)$, Paraphrasing $(M=3.92)$, Guessing the interlocutor's next word or sentence $(M=3.22)$, Coining words $(M=3.18)$, and Reading without looking up every new word $(M=3.14)$. However, comparison of the quantitative data with the findings of the other qualitative measures reveals some mild differences and modifications in terms of the compensation strategies, indicating some emerging trends in strategy use by the respondents, and possibly suggests the need to revamp current inventories in the field of LLS in the networked world.

The following comparison is based on Oxford's SILL (1989) that classifies compensation strategies into the following two groups respectively.

\section{Guessing Meaning}

The guessing meaning strategy helps language learners to intelligently guess a word's meaning by using surrounding words as linguistic and non-linguistic cues.

\section{Using Linguistic Clues}

In using the linguistic clues strategy, learners use "linguistic knowledge of suffixes, prefixes, and word order to guess meaning" (Oxford, 1990, p. 90). It is reported as a highly used strategy in the SILL data $(M=4.08)$. Study respondents reported guessing the meanings of unknown words by dividing them into their components, using their knowledge of the comprising parts, and adding them up again to comprehend meaning. For example, Sani reported dividing the word "inseparable" as being made of a "negative maker," a "stem that seems to be taken from separate" 
and a "suffix," altogether indicating "something you cannot separate." Another student, Sina, in his online interactions posted, "[I]'m kinda outdated when it comes to computers $\sim$ didnt even know what firewall means first when i bought a laptop, i just thought of a wall build to stop fire 9 "

Sina assumed the meaning of the word to be a wall or barrier to stop fire. He was right, as a firewall is designed to block some computer applications based on a set of commands. ict term ??"

A girl student posted to her group mate: "I come across term webinar, you think [it] is an

Her friend used the guessing strategy and answered, “Think is a word made of 'web' and 'seminar' meaning an online seminar (-) let me double check !!! (*)" She divided the word into two parts, used her knowledge of each part and, by "putting things together," guessed the meaning.

The guessing strategy seems to be used in both digital and printed media. However, the abundance of material in digital and online communications may increase the chance of encountering new words and result in greater opportunity for guessing meaning and, ultimately, for learning. Moreover, the abundance of blended and compound words emerging from new technology, such as "Widgets, Wiktionary, and Brexit," increase more frequent guessing chances on the Net. It is also possible to check and confirm the accuracy of guesses immediately in online situations, thus enhancing the effectiveness of learning. The strategy, accordingly, seems to be effective and employed more often in online interactions and networking.

\section{Using Non-Linguistic Clues}

This strategy is defined by Oxford (1990) as "seeking and using clues that are not languagebased in order to guess the meaning of what is heard or read in the target language and includes knowledge of context, situation, text structure, personal relationships, topic, or general world knowledge" (p. 49). The use of this strategy is reported at a medium level in the SILL data $(M=3.14)$. Study participants reported using various non-linguistic cues to compensate for missing knowledge, to guess the meaning of problematic parts, and to get a general view about the problem. The situation, interlocutor, register, and jargon can help the learners to get a rough meaning of the problematic part. For instance, Eren reported:

I was listening to [a] mentor in the church in a memorial ceremony and had problem understanding the word melancholy; actually I was not sure about its meaning although I had a rough guess like 'sorrow' as related to the situation. Later on I went to dictionary to check if my guess was correct.

In this case, the compensation strategy for missing knowledge was based on making association between place, interlocutor, and the context of the word's use. The student reported checking for the meaning later on to confirm her guess and encouraged herself to use the word in her speech production.

Another student remarked, "I notice plot and theme of the story that always help me in online reading."

Sang stated that she used the context and activity to understand meaning:

The first time I came across the expression 'knife him' in a game, I did not understand, I got it mean 'kill him' through motion in the game or the word 'finish' did not mean killing to me unless I saw the action 
Although it appears that Net-Generation students make extensive use of this strategy, they seem to pay less attention to minor contextual aspects as a result of their global and holistic viewpoints. Net-Geners tend to be more field-independent and prefer to focus on the whole picture, leaving minor parts unnoticed, possibly through the abundance of information on the Net. For example, Wong Chi reported:

When I don't understand particular terms on the net, I would explore the meaning only if I find it is crucial in doing so. I highlight more on the overall picture and content to understand rather than the minor things in it

She emphasized checking online for the information only if it was necessary and that she used the general content to understand the meaning of the problematic parts.

Although data from the SILL indicate medium-level use of the strategy, qualitative data show that the strategy tends to be used more by the Net-Geners, possibly as a result of the abundance of various materials on the Net and increased exposure to information. They seem to like quick understandings of unknowns, use abundant linguistic and non-linguistic clues on the Net, and focus on a broad, conceptual meaning rather than minor points.

\section{Overcoming Limitations in Speaking and Writing}

Strategies for overcoming difficulties in speaking and writing are divided into the following six types:

\section{Switching Back to Mother Tongue}

Oxford explains the strategy of switching back to mother tongue as "using the mother tongue for an expression without translating it in speaking" (1990, p. 94). As a compensation strategy, it is used when learners face difficulties while "speaking" in the second language. The strategy is not explicitly addressed in the SILL (Oxford, 1989) items. However, it was noted that some informants of the study used Malay words in their spoken communication that were impossible for the researcher to catch because of his unfamiliarity with Bahasa Melayu. For that reason, a co-rater (a Malaysian Master student of language) was asked to check the online English interaction texts for any possible trace of Malay words or structures used by the informants of the study. Based on Oxford's discussion, reverting to the mother tongue for pre-internet generations of learners tends to be associated with oral communication but data from this study show that NetGeners use the strategy in their electronic "written" form as well. There seems to be little hesitation in using mother-tongue words in their second language online communication (considered as "speaking" for Net-Geners). For example, Rizah posted: "i sayang u lebih [ I love you more] laaaa.... hehehe.... $\Theta$ just kidding..."

Another example comes from the way Nani addressed Mun and called her cikmun to mean 'Miss Mun' in her online post.

The language used in electronic interaction or discourse seems to be a variation of language in which grammatical norms of written language are carelessly breached and mixed with informal spoken language. In addition, the use of code switching is comfortably accepted in online communication, even in academic discussions, just as it would be in spoken interactions. Code switching as one of the communication strategies in which the learner switches back to his/her mother tongue to fill the linguistic knowledge gap to convey the message existed in the research data collection. Although primarily associated with the spoken language, code switching, surprisingly, was used to convey the message in the online written forum. Code switching caused 
no trouble in online interactions, accepted by others with little complaint. This caused the authors to recognize code switching as an accepted means of communication in the online interactions. The authors generally believe that the Net-Geners are more flexible than previous generations and can accept and understand problematic issues with more ease. This flexibility may be the result of access to widespread sources and vast amounts of information which, at times, may conflict. As Tornow (1997) argues, "the past distinction between writing and talking is blurred in E-texts" (p. 1). There seems not to be a firm discrimination between the spoken and written forms of language in Net-Geners' online interactions.

\section{Getting Help}

Oxford defines the getting help strategy as implicitly "asking someone for help in a conversation by hesitating or explicitly asking for the missing expression" (1990, p. 95). This strategy, however, is not explicitly addressed in the SILL (Oxford, 1989) items.

About 90 percent of the students indicated that they directly asked their online buddies to help them with their language problems. Data from open-ended questionnaire entries also supported the case. For example, one student posted, "I usually ask my online buddies for my language problems and ask them to let me know if I make mistakes."

Another student posted, "[C]ould you please explain it to me... brainee [sic]..huhu.."

Similarly, Nash emphasized his almost constant online connection and queries from his online friends: "I ask my friends in the chat room where I spend most of my time."

Social networking affordances seem to have increased the level of intimacy between NetGeners, despite their geographical, and possibly social, distances, thereby encouraging them to reduce learning barriers and increase their language intake from accessed sources, authorities, and peers to simply ask for and share their language information with others.

Nearly 20 percent of participants indicated that they consult their lecturers for their language problems as well. The excerpt from Willi addresses the strategy: "I ask my friends and lecturers to help me with my language problems."

Another student tried to help her friend and posted, "[A]ctually to come to think of it i'm confuse now. It's k i'll ask the lecturer and let you know

The importance of the classroom teacher as the source of information, ready to help students with their language learning problems, is highlighted in the reported excerpts.

Some students also reported going online and getting in touch with native English speakers. Easy access to native speakers of English and having 'Net friends' from a native English-speaking community is obviously possible as a consequence of Network development. This helps NetGeners to improve their language learning and attain proximity to, and understanding of, the target language culture. The Internet has provided people all around the world with real-time communication possibilities through social networking facilities. In fact, everything and everyone seem just a few clicks away. Net-Geners can extensively use this rather new facet of the getting help strategy in their language learning procedure.

While in Oxford's discussion, the strategy is limited to conversation that logically refers to face-to-face interaction due to the blurred distinction between writing and speaking in online discourse, the strategy tends to be highly used in the online interaction of the Net-Geners' electronic written language as well. Net-Geners can easily get help from their peers, lecturers, 
native speakers and, in some cases, through random online connections. For instance, lecturers can easily prepare, record, edit, and upload their lectures in small and manageable bites (e.g., using Camtasia) and give students the flexibility to listen or view the materials at any time. Discussion boards also give both students and lecturers the opportunity to share opinions, ask questions, and make comments through Internet communication. In addition, many lecturers use email, Tweeter, My Space and Facebook to interact with students and receive their questions. Online communication and limitless connection between Net-Geners seem to have developed a kind of camaraderie among them that allows for giving help and requesting information without awkwardness. Getting in touch with the lecturers seems also to be less problematic for Net-Geners because students can easily access their lecturers without time and space limitations through their posts, emails, or blogs.

\section{Using Mime and Body Movement}

Using mime and body movement strategy is defined as using "physical motion, such as mime or gesture, in place of an expression during a conversation to indicate the meaning" (Oxford, 1990, p. 95). Data from the SILL indicate high use of this strategy among participants (using gesture, $M=3.97$ ). Interview data show this strategy used to express intended meaning, to ask about problems, or even to get approval and confirmation about their understanding in face-to-face interactions. Pari, for example, remarked, "I use gestures, body movement, facial expressions, and hand movement in case I have problems understanding others or expressing myself."

While the strategy use seems to pertain to face-to-face conversation in the SILL item, data from online interactions and interviews indicate frequent use of this strategy in the electronic environment. However, the absence of face-to-face contact in online interactions and chat rooms necessitate a variation of the strategy, and invites the use of compensatory measures such as emoticons.

Information query through icons and textual techniques is easily observed in the students' online interactions where absence of direct eye contact brings communication of nonverbal information query to a halt. In response, Net-Geners frequently use emoticons and iconic language to ask for information. For example, Anis showed his bewilderment about the term 'action maze' by using an icon and four question marks and asked for information, "[A]nyone could explain it [action maze] to me????

Iconic language was also used to represent facial expressions such as laughter, anger, and frowning. For example, Anadi, in order to show her consent, posted a laughing icon to her friend: "It is okay. Thanks for your concern $\theta$ ",

Happiness and consent are expressed in a more creative manner in Rosa's post: "[A]big

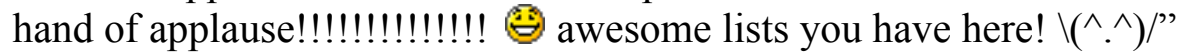

She used iconic language and also made creative use of exclamation marks and textual facilities to represent a happy icon.

Students frequently tend to use emoticons and other animation-driven textual techniques such as :-) for smile, :-o for shock, :-( for frowning, and even more creative and complex ones such as $\backslash\left(\wedge^{\wedge}\right) /$ for happiness, $a^{\wedge} \_@$ for blushing. The strategy use for Net-Generation language learners in this study seems to extend to written online communication and is not limited to faceto-face interaction. 


\section{Adjusting or Approximating the Message}

Adjusting or approximating the message strategy is explained as "altering the message by omitting some items of information, making the ideas simpler or less precise, or saying something slightly different with similar meaning" (Oxford, 1990, p. 96). It seems to be consistent with the SILL item regarding the guessing the interlocutor's next word or sentence with a reported mediumlevel use mean value of 3.22. The strategy as discussed by Oxford entails speaking as well as writing dynamics. However, in online communication, a new visual facet of this compensatory strategy emerged. Merik, for instance, reported, "In case of having problem expressing what I mean online, I may search for an image or picture and send it to the other party to make her understand."

This strategy use was based on her justification that "a picture is more expressive in that it provides a mental image in the mind and conveys more meaning."

Respondents believed that their vast and instant access to online materials make it possible to look for words or concepts while they are communicating online and sharing their ideas with others. For example, Cafren remarked, "When I am Facebooking, it's easier to understand coz [sic] you see things, you can check online to learn and share it."

The strategy use seems to be facilitated for the Net-Generation language learners with modern online affordances equipped with visual modes. They tend to use the pictorial mode of the strategy as a quick, exact, and expressive way of conveying the message, in that it may leave a long-lasting effect in their minds as well as that of their interlocutors, in online communications. This facet of compensation strategy is not explicitly addressed in the SILL (Oxford, 1989) and seems to emerge from the study.

\section{Avoiding Communication Partially or Totally}

"Avoiding communication partially or totally" is explained as "avoiding communication when difficulties are anticipated or encountered" (Oxford, 1990, p. 95). The strategy, although not addressed in the SILL items, is reported in the interviews. Students reported the strategy use both in face-to-face and online communications. For example, when Pari spoke about difficult words and complex English sentence structures, she simply said: "I prefer not to talk about difficult things."

In online interactions, the strategy use seems more convenient for the Net-Generation language learners, as they are almost always connected with their friends through social networking interfaces. As a result of the absence of face-to-face contact and the feeling of embarrassment and awkwardness of not knowing what to say, they felt that it was easier to avoid unfamiliar or odd discussions or to avoid the conversation if they had language problems. For example, Aftim reported, "In online communication, I just skip the idea if I don't know how to say it."

Another student, Pari, believed that when she is online, it is easier to keep silent and not feel awkward when facing problems in expressing herself: "In the chat room, I just keep silent if the language is difficult for me to join."

The strategy was first suggested by Oxford (1989) for speaking and oral communication but in this case, the strategy use seems to extend to online written discourse. 


\section{Coining Words}

Coining words is defined as "making up new words to communicate the desired idea" (Oxford, 1990, p. 50). In the SILL data, it was reported as a medium-level use strategy $(M=3.18)$. Internet and widespread socialisation facilities have brought about new terms and conventions not previously found in the pre-internet era. Observation of online interaction texts reveals that the Net-Geners tend to use newly coined words or shortened forms of the words in online and digital communications to save time. Some examples are: TTFN (Tata for now), OMG (Oh my God), LOL (Laughing out loud), and SYL (See you later).

The respondents tend to use these recently coined words to facilitate their communication and also coined words of their own. For example, Adjernest said, "Last night I was ooVooing my mom who live [sic] in another country."

When asked about "ooVooing," she explained that "ooVoo" is an application that makes it possible to video chat on the net with 12 people simultaneously from all over the world. She added a suffix to the "noun" as if it were a "verb," similar to what is done to "texting" for sending an SMS. The strategy use seems to be facilitated by wide access to the Internet and daily exposure to increasing compound and blended ICT words, which makes it easier for the Net-Geners to coin new words without feeling odd.

Communication, especially in its online form, seems impaired without coined words, signs, and icons. Their literacy and use appear to be a must for the Net-Geners' online communication.

\section{Conclusion}

As for the emerging compensatory strategies, it was reported that compensatory strategies were repeatedly used by study participants, but some modifications in the strategy use seemed to be applicable in the online communications of the Net-Geners in their language learning tasks. Guessing strategy tended to be used more in online interactions and networking due to the abundance of materials, and blended and compound words emerging from the new technology.

Non-linguistic cues tended to be used more by the Net-Geners, possibly as a result of their use of the digital games through which Net-Geners can quickly absorb the meaning of lexical items by use of plot and context. There seemed to be little hesitation in using mother-tongue words in their second language online written communication. This Code switching used to be characteristic of spoken language; however the borderline between the spoken language and its written form seem to be blurred (Tornow, 1997).

Social networking affordances seemed to have increased intimacy between Net-Geners in spite of their geographical and possibly social distances. They simply ask for, and share, their language information with others. Net-Geners extensively used this rather new facet of the getting help strategy in their language learning procedure. The new social networking applications make it possible for the learners of the digital era to comfortably ask for any unknown information and consequently, increase their competence. This increased knowledge, in turn, can lead to better performance, both in online and offline communication. Net-Geners feel free to ask questions and answer other learner's questions, possibly as the result of more online interaction and networking.

Mime and gestures strategy pertained to face-to-face conversation in pre-internet learners for communication of feelings and information query. However, the absence of face-to-face 
contact in online interaction and networking necessitated a variation of the strategy and invited the use of compensatory measures such as iconic language and stickers in the online written communication. The existence and application of iconic language, along with Net-Geners' creativity, led to the creation of new forms of icons with specific social meanings. Avoidance strategy use, on the other hand, seemed to extend to online written discourse, although it was first suggested for speaking. Of course, it seems much easier to withdraw from an online communication, possibly because of the lack of eye contact. Also, it seems very comfortable to avoid "avoidance strategy" as there is access to an abundance of information on the Net which could easily be Googled and used at lightning speed.

Net-Geners tended to use the pictorial and visual mode to adjust their message as a quick, exact, and expressive way of conveying their message. This seemed to be in harmony with their visual and pictorial tendency in their online and offline language learning. The visual inclination may have been formed as the result of playing online and digital offline games in which they have to gaze at the screen and actively watch for every single movement from the "enemy front" and quickly respond to it. This quality may have turned Net-Geners into super viewers who are very attentive and also ready to interact with their learning context. They seemed to enjoy using newly coined words to facilitate their communication and also to coin words on their own for ease in their online interactions.

\section{Implications}

Net-Gener language learners have embraced new technology and have found ways to cope with its facilities and compensate for its limitations. As mentioned earlier, they seem to adopt networking for every act of their ordinary and academic life. Digital media and networking have become part of the habits and expectations of these Net-Generation learners. Their study and learning, therefore, cannot be exceptions. For the purpose of this study, i.e. the use of compensation strategies in the online forums, students were observed to communicate their non-verbal expressions in pictographic form, using emoticons or the iconic images to show their emotions to their interlocutor who is possibly far away from them both in terms of time and place. Although the Oxford SILL questionnaire seems deficient for the incorporation of digital compensation strategy items in the digital age and did not point to the considerations of this study, it is still compatible with the necessities of the new digital era, although, the item, "** In online communication, I use emoticons and other textual forms to express a lack of understanding and a need for assistance," is suggested for Inclusion in the SILL Compensation Strategies Category.

But many other compensatory concerns of SILL need modifications for the current Netbased language learning.

While the present findings suggest a need for the above addition or modification to existing items in the SILL categories, future and extended research on language learning strategies of NetGeners may, in fact, point to a possible reconceptualization of the categories themselves and, conceivably, a new inventory for the language learning in the digital age. Such an undertaking is beyond the scope of this study but definitely requires further investigation. The findings may also show language educators and teachers ways to deal with their Net-Generation language students and to set their learning objectives accordingly. 


\section{References}

Ardasheva, Y., \& Tretter, T. R. (2012). Perceptions and use of language learning strategies among ESL teachers and ELLs. TESOL Journal, 3(4), 552-585. doi: 10.1002/tesj.33

Bandura, A. (1992). Social cognitive theory. In R. Vasta (Ed.), Six theories of child development: Revised formulations and current issues (Vol. 6, pp. 1-60). London: Jessica Kingsley Publishers.

Breen, M. P. (2014). Learner contributions to language learning: New directions in research. NY, USA: Routledge.

Chamot, A. U. (2005). Language learning strategy instruction: Current issues and research. Annual Review of Applied Linguistics, 25, 112-130.

Chamot, A. U., Barnhardt, S., El-Dinary, P., \& Robbins, J. (1996). Methods for teaching learning strategies in the foreign language classroom. In R. L. Oxford (Ed.), Language learning strategies around the world: Cross-cultural perspectives (pp. 175-188). Honolulu, HI: University of Hawai'i Press.

Chamot, A. U., \& Kupper, L. (1989). Learning strategies in foreign language instruction. Foreign Language Annals, 22, 13-24.

Chamot, A. U., \& O'Malley, J. M. (1994). Teaching for Strategic Learning: Theory and Practice. In J. E. Alatis (Ed.), Georgetown University Round Table on Languages and Linguistics 1993. Washington, D.C: Georgetown University Press.

Chapelle, C. A. (2009). The Relationship between Second Language Acquisition Theory and Computer-Assisted Language Learning. The Modern Language Journal, 93, 741-753. doi: $10.2307 / 25612271$

Cohen, A. D., \& Macaro, E. (2008). Language learner strategies: 30 years of research and practice. Oxford, UK: Oxford University Press.

DeKeyser, R. (2015). Skill acquisition theory. In B. VanPatten \& J. Williams (Eds.), Theories in second language acquisition: An introduction (pp. 94-112). NY: Routledge.

Dörnyei, Z., \& Ryan, S. (2015). The psychology of the language learner revisited. New York, NY: Routledge.

Dunne, D., \& Martin, R. (2006). Design thinking and how it will change management education: An interview and discussion. Academy of Management Learning \& Education, 5(4), 512523.

Edstrom, A. (2013). Preparing an L2 Role-play: How Students Manage L2 Deficits. Canadian Modern Language Review, 69(3), 274-297. 
Hajhashemi, K., Shakarami, A., Anderson, N., Yazdi-Amirkhiz, S. Y., \& Zou, W. (2013). Relations between Language Learning Strategies, Language Proficiency and Multiple Intelligences. Academic Research International, 4(6), 418-429.

Hampel, R., \& Baber, E. (2003). Using internet-based audio-graphic and video conferencing for language teaching and learning. In U. Felix (Ed.), Language Learning Online (Language Learning and Language Technology (Vol. 3, pp. 38-41). Lisse, Nertherlands: Swets \& Zeitlinger.

Hauck, M., \& Hurd, S. (2005). Exploring the link between language anxiety and learner selfmanagement in open language learning contexts. European Journal of Open, Distance and e-Learning, 2.

Heidar, D. M. (2012). First Language Acquisition: Psychological Considerations and Epistemology. Theory and Practice in Language Studies, 2(2), 411-416.

Hsiao, T., \& Oxford, R. L. (2002). Comparing Theories of Language Learning Strategies: A Confirmatory Factor Analysis. Modern Language Journal, 86(1), 368-383.

Mitchell, R., Myles, F., \& Marsden, E. (2013). Second Language Learning Theories ( ${ }^{\text {rd }}$ ed.). NY: Routledge.

O’Malley, J. M., \& Chamot, A. U. (1990). Learning Strategies in Second Language Acquisition. Cambridge, England: Cambridge University Press.

Oblinger, D. G., \& Oblinger, J. L. (2005). Is it age or IT: First steps toward understanding the Net generation. In D. G. Oblinger \& J. L. Oblinger (Eds.), Educating the net generation (pp. 2.1-2.20). North Carolina, State University: Educause.

Oxford, R. L. (1989). Use of language learning strategies: A synthesis of studies with implications for strategy training. System, 17(2), 235-247. doi: http://dx.doi.org/10.1016/0346-251X(89)90036-5

Oxford, R. L. (1990). Language learning strategies: What every teacher should know. Boston: Heinle \& Heinle.

Prakongchati, N. (2007). Factors related to the use of language learning strategies by thai public university freshmen $\mathrm{PhD}$ thesis. Suranaree University of Technology. Retrieved from http://sutir.sut.ac.th:8080/sutir/bitstream/123456789/283/1/nisakorn_fulltext.pdf

Radwan, A. A. (2011). Effects of L2 proficiency and gender on choice of language learning strategies by university students majoring in English. The Asian EFL Journal Quarterly March 2011, 13(1). 
Rezaei, S., Derakhshan, A., \& Bagherkazemi, M. (2011). Critical thinking in language education. Critical Thinking in Language Education, 2(4), 769-777. doi: 10.4304/jltr.2.4.769-777

Rovali, A. P. (2004). A constructivist approach to online college learning. Internet and Higher Education, 7(1), 79-93.

Salahshour, F., Sharifi, M., \& Salahshour, N. (2013). The Relationship between Language Learning Strategy Use, Language Proficiency Level and Learner Gender. Procedia Social and Behavioral Sciences, 70, 634-643. doi: http://dx.doi.org/10.1016/j.sbspro.2013.01.103

Shakarami, A., Abdullah, M. H., Abdullah, F. S., \& Hoon, T. B. (2011). Remembering differently: Use of memory strategies among net-generation ESL learners. Educational Research and Reviews, 6(4), 350-357.

Spivey, N. N. (1997). The Constructivist Metaphor:Reading, Writing, and the Making of Meaning (Vol. 1). San Diego: Academic Press.

Tang, M., \& Tian, J. (2014). Associations between Chinese EFL graduate students' beliefs and language learning strategies. International Journal of Bilingual Education and Bilingualism, 18(2), 131-152. doi: 10.1080/13670050.2014.882882

Tornow, J. (1997). Link/age: Composing in the on-line classroom. Logan, UT: Utah State University Press.

VanPatten, B. (2015). Input processing in adult second language acquisition. In B. VanPatten \& J. Williams (Eds.), Theories in second language acquisition: An introduction (pp. 113134). NY: Routledge.

Vassiliki, S., \& Marie-Josee, H. (2005). CASLA through a social constructivist perspective: WebQuest in project-driven language learning. ReCALL, 17(2), 217-228.

Vygotsky, L. S. (1978). Mind in society: The development of higher psychological processes. Cambridge, Massachusetts: Harvard University Press.

Wenden, A. (1991). Learner strategies for learner autonomy. London: Prentice -Hall International.

White, C. (1995). Autonomy and strategy use in distance foreign language learning: Research findings. System, 23(2), 207-221. 